\title{
PELUANG EVENT PARIWISATA DALAM MENGATASI UNSUSTAINABILITY TOURISM DI PANTAI KELAPA PATIMBAN PUSAKANAGARA KABUPATEN SUBANG
}

\author{
R. Hendro S. Arlianto \\ Program Studi Magister Pariwisata Berkelanjutan SPs \\ Universitas Padjadjaran Bandung \\ Email: rd.hendro.sa@gmail.com \\ Evi Novianti \\ Program Studi Magister Pariwisata Berkelanjutan SPs \\ Universitas Padjadjaran Bandung \\ Email: evi.novianti@unpad.ac.id \\ Cipta Endyana \\ Program Studi Magister Pariwisata Berkelanjutan SPs \\ Universitas Padjadjaran Bandung \\ Email: cipta.endyana@unpad.ac.id
}

\begin{abstract}
This study discusses the holding of an "event" which is an opportunity to overcome the situation of unsustainability tourism in Pantai Kelapa Patimban, Subang. Furthermore, this study explains the importance of coordination with various interested parties in organizing "events". Descriptive studies are used to examine more in depth the situation of the Patimban Coconut Coast which is in a crisis situation after the mega International Port development project began in 2015. The results of the study in the discussion section led to a number of interesting findings, including the fact that the "event" must consider many things and is not as simple as determining the "event" in what field, who is the event host, and who is the target participant / visitor. There are many factors that must be considered to support the smooth implementation of "events" starting from the stage of pre-preparation (event designing), preparation (event preparation), the implementation (event execution), and evaluation (event evaluation). These factors can be learned from other disciplines. The author hopes that through this writing, the author can provide ideas or ideas to bring back the Coconut Patimban Beach to sustainability tourism in the future.
\end{abstract}

Keywords: Tourism, sustainability tourism, unsustainable tourism, event, event tourism 


\section{Pendahuluan}

Pemetaan potensi pariwisata di Kabupaten Subang, Provinsi Jawa Barat belakangan ini semakin menarik untuk diwacanakan. Analisa terhadap kehadiran perencanaan strategis nasional (PSN) Pelabuhan Internasional Patimban telah mengundang kajian demi kajian hadir dati berbagai sudut pandang, termasuk di bidang kajian dengan menggunakan pendekatan sustainable tourism. Akan tetapi kondisi sesungguhnya yang terjadi semenjak masa proses pembangunan mega proyek pelabuhan Internasional Patimban diketahui adanya situasi-situasi pembatasan lahan sekitar daerah pantai yang menyebabkan terjadinya unsustainability tourism di wilayah tersebut.

Dengan dukungan data jumlah wisatawan yang berkunjung ke destinasi wisata di sekitar Subang, penulis tertarik untuk mengembangkan sebuah tulisan yang membahas bagaimana potensi pariwisata berkelanjutan yang dimiliki oleh kawasan wisata di sekitar Pelabuhan Internasional Patimban di Kabupaten Subang. Hal ini dilakukan dengan pertimbangan pentingnya pondasi data sebagai dasar pengembangan potensi suatu daerah, dalam konteks ini khususnya terkait potensi pariwisata berkelanjutan yang tidak lama lagi akan hadir dan berkembang dengan pesat di Kabupaten Subang dengan dibangunnya Pelabuhan Internasional Patimban yang ditargetkan gelar soft launching di akhir tahun 2019.

Konsep yang digunakan dalam melakukan kajian ini adalah ide dan gagasan dari Gertz (2007) tentang Event tourism. Konsep tentang event tourism dari Gertz (2007) membahas tentang penyelenggaraan "event" yang berhubungan dengan berbagai bidang profesional lain. Lebih lanjut, konsep ini juga menjelaskan bagaimana pentingnya kordinasi dengan berbagai pihak yang berkepentingan dalam penyelenggaraan "event", misalnya bagian produksi dan marketing. Event tourism (acara pariwisata) merupakan sebuah pasar bagi pengelola acara dan sebuah alat pengembangan destinasi sebagai tujuan pariwisata. Kini acara pariwisata telah 
diakui secara umum sebagai suatu kegiatan tersendiri yang memiliki pendekatan dan pengembangan khusus.

Selanjutnya Gerz (2007) mendefiniskan bahwa "event" merupakan alat komunikasi, media dan pertunjukan, studi budaya memberi pemahaman bahwa dalam sebuah "event", budaya merupakan salah satu hal yang penting dan harus selalu diperhatikan sebagaimana faktor sosial. Studi budaya ini memberikan pandangan yang kritis terhadap budaya pop yang saat ini menjelma di berbagai bentuk "event".

Menurut Getz (2007), sebuah "event" adalah suatu kejadian yang tidak bisa diulangi karena hanya terjadi satu kali. Acara terencana atau "planned event" meskipun memiliki wujud dan konsep yang sama tetapi selalu ada variabel lain dalam acara tersebut akan berbeda sehingga akan menimbulkan pengalaman yang berbeda. Berdasarkan beberapa konsep dari literatur yang akan digunakan, maka penulis berusaha untuk merumuskan kajian permasalahan dalam tulisan ini menjadi satu fokus kepada peluang event tourism dalam mengantisipasi potensi unsustainability tourism di Pantai Kelapa Patimban.

\section{Metodologi}

Metode yang digunakan dalam penulisan ini dapat digolongkan sebagai deskriptif kualitatif. Melalui metode ini penulisan yang dilakukan terbatas pada usaha mengungkapkan suatu permasalahan, keadaan, peristiwa atau bahkan fenomena sebagaimana adanya sehingga bersifat penggambaran terhadap fakta yang terjadi. Hasil analisa atau pembahasan pada tulisan ini diarahkan pada pemberian gambaran secara obyektif tentang topik kajian yang dibahas.

Ada dua jenis data yang diperlukan dalam kajian ini, yakni data yang bersifat primer dan data yang bersifat sekunder. Untuk melakukan pengumpulan data, 
penelitian ini menggunakan tiga tehnik, yaitu studi pustaka (data sekunder), wawancara mendalam dengan informan yang memiliki kompetensi dalam terkait.

Analisis data adalah proses mencari dan menyusun secara sistematis data yang diperoleh dari hasil wawancara, catatan lapangan dan dokumentasi dengan cara mengorganisasikan data kedalam kategori, menjabarkan ke dalam unit-unit, melakukan sintesa, menyusun dalam pola, memilih mana yang penting dan yang akan dipelajari dan membuat kesimpulan sehingga mudah di fahami oleh diri sendiri dan orang lain menurut (Sugiyono, 2012 ; Shiddiq, 2012).

Menurut Miles dan Hubermen (1992) dalam Idrus (2009: 148), Dalam pengelolaan data kualitatif ada yang di sebut model interaktif yang terdiri dari 3 hal yaitu reduksi data, penyajian data dan penarikan kesimpulan/verifikasi untuk membangun wawasan umum. Peneliti sendiri menggunakan analisis data melalui tahapan yang dikemukaan Miles dan Huberman seperti dalam gambar 3.2 yang menggambarkan tahapan dalam analisis data.

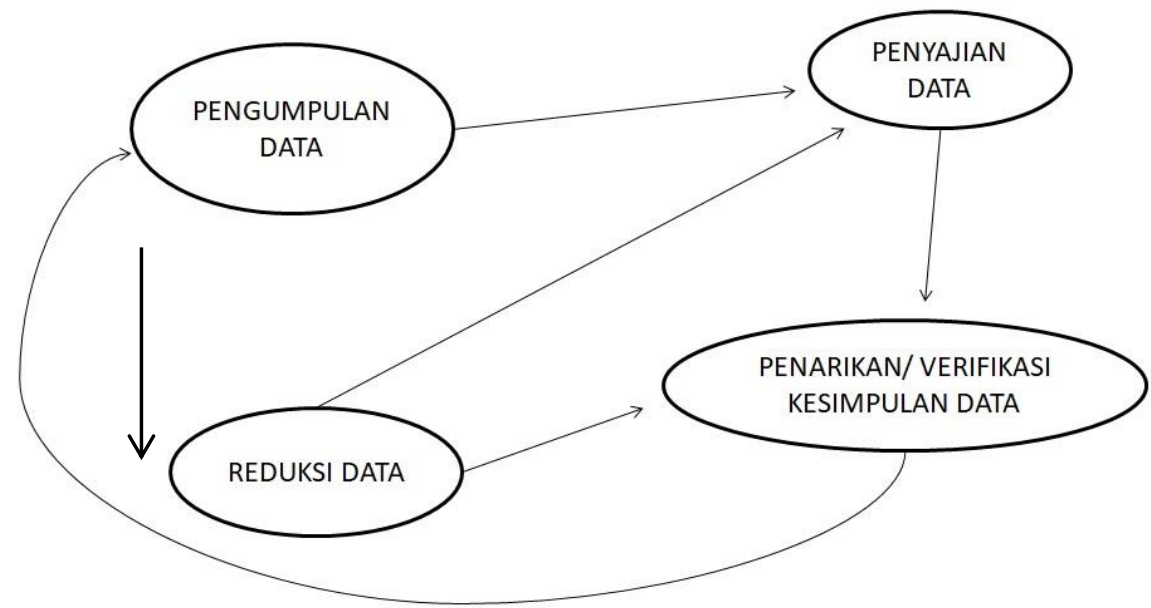

Gambar 1. Model Interaktif Miles dan Huberman

Sumber : Olahan peneliti 2018

Analisis data yang dilakukan dari hasil FGD, survei lapangan, wawancara yang digabung menjadi data deskriptif kualitatif yang menggambarkan keada dan situasi lapangan setelah mendeskripsikan langkah kedua Data yang diperoleh di 
rangkum, lalu di pilih hal-hal yang pokok, fokus pada hal-hal yang penting, dicari tema dan polanya. Dengan demikian data yang telah di reduksi akan memberikan gambaran yang jelas dan mempermudah peneliti untuk melakukan penariakn kesimpulan.

\section{Hasil Penelitian dan Pembahasan}

Subang memiliki destinasi wisata yang lengkap mulai dari pegunungan hingga pantai lengkap dengan pelabuhan internasional yang sedang pada tahap pembangunan. Situasi tersebut memberikan peluang pariwisata yang luas untuk dikembangkan ke depannya. Dalam kesempatan kali ini penulis berusaha untuk mengkaji peluang pariwisata di Pantai Kelapa Patimban yang disinyalir mengalami kondisi unsustainability tourism semenjak dilaksanakannya mega proyek pelabuhan internasional Patimban.

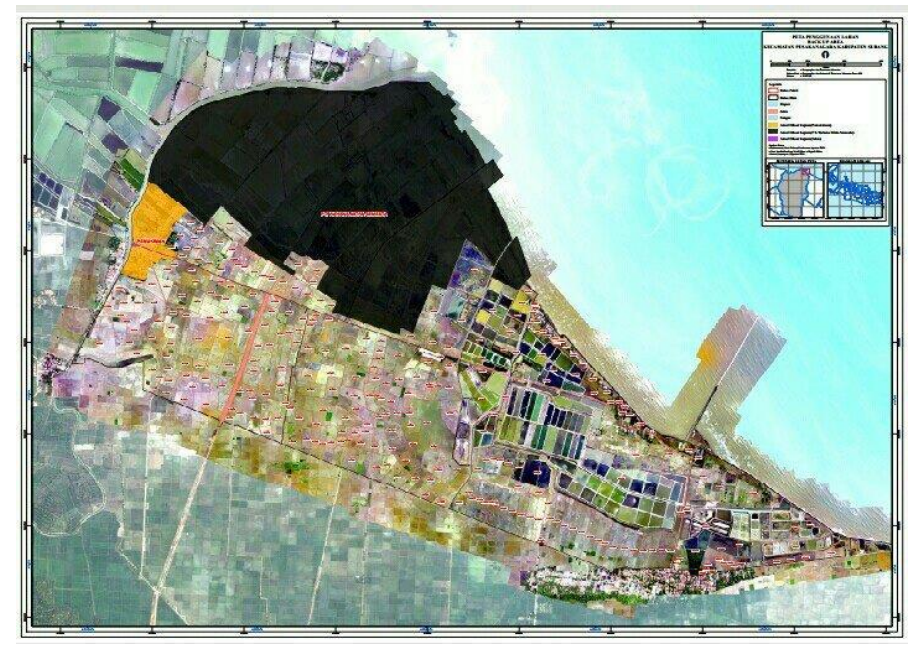

Gambar 2. Peta Wilayah Pelabuhan Internasional Patimban

Pada awal pembangunan mega proyek pelabuhan internasional Patimban warga memiliki sejumput harapan untuk semakin berkembangnya pariwisata di sekitar Pantai Kelapa Patimban yang memiliki potensi kuliner ikan etong. 


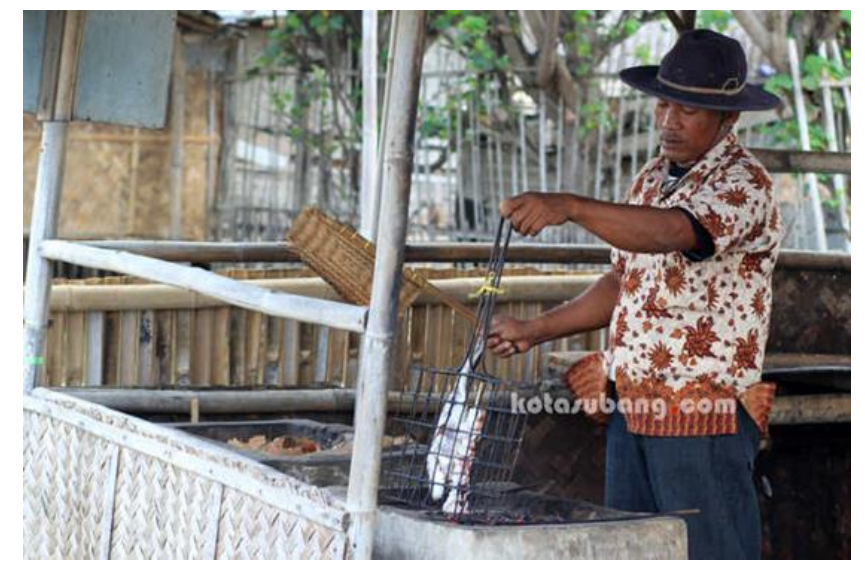

Gambar 3. Warsa Sedang Memanggang Ikan Pesanan Pengunjung Sumber: www.kotasubang.com

Akan tetapi jauh panggang dari api, ketika pengembang membangun pantai patimban menjadi Kawasan Wisata Bahari Grand Patimban seiring dengan pemerintah pusat juga membangun pelabuhan peti kemas penyangga pelabuhan Internasional Tanjung Priuk di Patimban. Kondisi memprihatinkan malah menerpa sejumlah pemilik usaha warung makan ikan bakar etong di kawasan Pantai Kelapa Patimban. Situasi wisata yang tadinya ramai menjadi sepi tak terkendali sejak pembangunan pelabuhan internasional dijalankan. Kondisi perekonomian sejumlah warung pun diterpa krisis berkepanjangan. Janji demi janji pemerintah untuk memberikan penggantian kerugianpun tak kunjung dipenuhi.
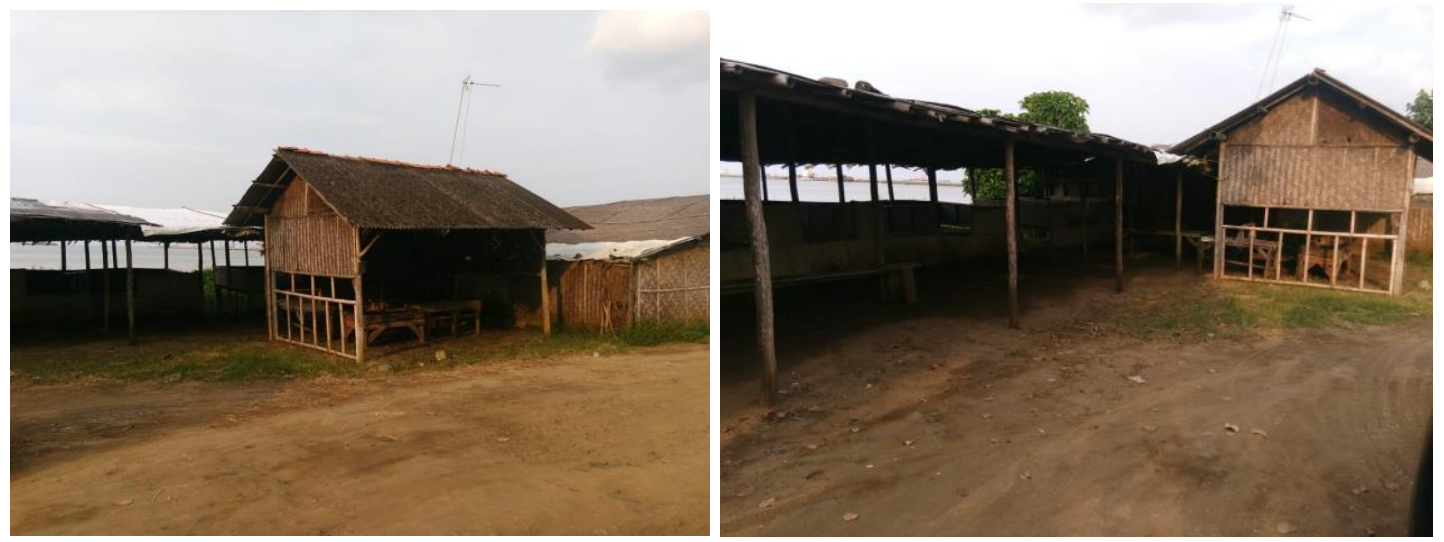

Gambar 4. Foto Warung Ikan Bakar yang sudah ditinggalkan penghuninya 


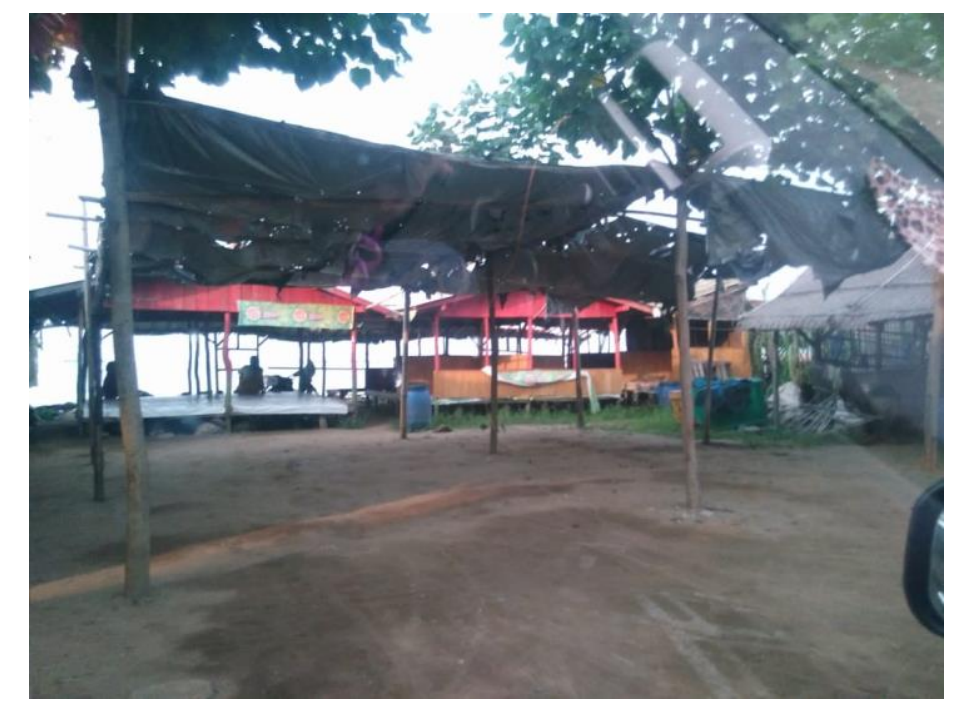

Gambar 5. Foto warung yang mulai hancur

Kondisi yang tidak menguntungkan tersebut membuat penulis terdorong untuk menggali lebih dalam dimana terjadi kesenjangan antara harapan dan kenyataan. Pembangunan pelabuhan Internasional Patimban secara blue print tentu saja menuai harapan besar meningkatkan perekonomian masyarakat Patimban termasuk meningkatkan pendapatan dari sektor pariwisata. Akan tetapi pada kenyataannya semenjak pembangunan dimulai justru jumlah wisatawan yang berkunjung ke Pantai Kelapa Patimban sambil menikmati lezatnya kuliner khas ikan bakar etong di pinggir pantai menjadi pemandangan yang semakin langka. Apakah situasi tersebut hanya bersifat sementara ? Melalui kajian penulisan ini penulis ingin mengetahui lebih dalam situasi unsustainability tourism yang menerpa Pantai Kelapa Patimban, sekaligus menilik peluang event untuk membuka kembali akses kepada sustainability tourism Pantai Kelapa Patimban di masa depan.

Event tourism (acara pariwisata) merupakan sebuah pasar bagi pengelola acara dan sebuah alat pengembangan destinasi sebagai tujuan pariwisata. Kini acara pariwisata telah diakui secara umum sebagai suatu kegiatan tersendiri yang memiliki pendekatan dan pengembangan khusus. Studi manajemen dan pariwisata membantu penyelenggara "event" untuk merencanakan atau mengembangkan 
kegiatannya agar berkaitan dengan objek wisata yang ada dan mampu menarik pengunjung sehingga mendatangkan keuntungan lebih.

Salah satu faktor yang berkontribusi terhadap kualitas "event" yaitu keramahan atau "hospitality" antara "host" penyelenggara dan "guest" tamunya. Pelayanan dalam bentuk keramahan sangat berkaitan dengan fasilitas rekreasi "leisure facility" karena memberikan kesan positif kepada pengunjung/peserta dan membentuk pengalaman yang baik, sehingga pengunjung/peserta mau datang/ikut serta lagi. Oleh sebab itu keramahan atau "hospitality" merupakan kunci utama kesuksesan penyelenggaraan sebuah "event".

Edukasi menjadi salah satu bidang yang banyak memiliki "event", di antaranya seperti seminar, dan konferensi, rapat. Pada penyelenggaraannya, karena berkenaan dengan bidang edukasi, maka pengunjung diharapkan dapat juga 'belajar' dari "event" tersebut. Hal itu disebabkan karena konten "event" juga berisi materi yang harus mampu tersampaikan kepada pesertanya. Oleh sebab itu, penyelenggara harus memperhatikan "way" atau cara bagaimana materi tersebut disampaikan, salah satunya dengan mempelajari dan menerapkan teori pembelajaran "learning theory". Selanjutnya yaitu interpretasi. Interpretasi ini berkaitan dengan wisata pameran/pertunjukan yang biasanya berisi symbol atau tanda. Tentu saja "event" yang berkaitan dengan hal tersebut memiliki tujuan yang ingin disampaikan. Misalnya museum angkut yang menunjukkan bagaimana perkembangan kendaraan di darat. Dalam hal ini, penyelenggara harus memikirkan bagaimana "display" yang tepat, agar pengunjung dapat memahami informasi yang ingin disampaikan. 


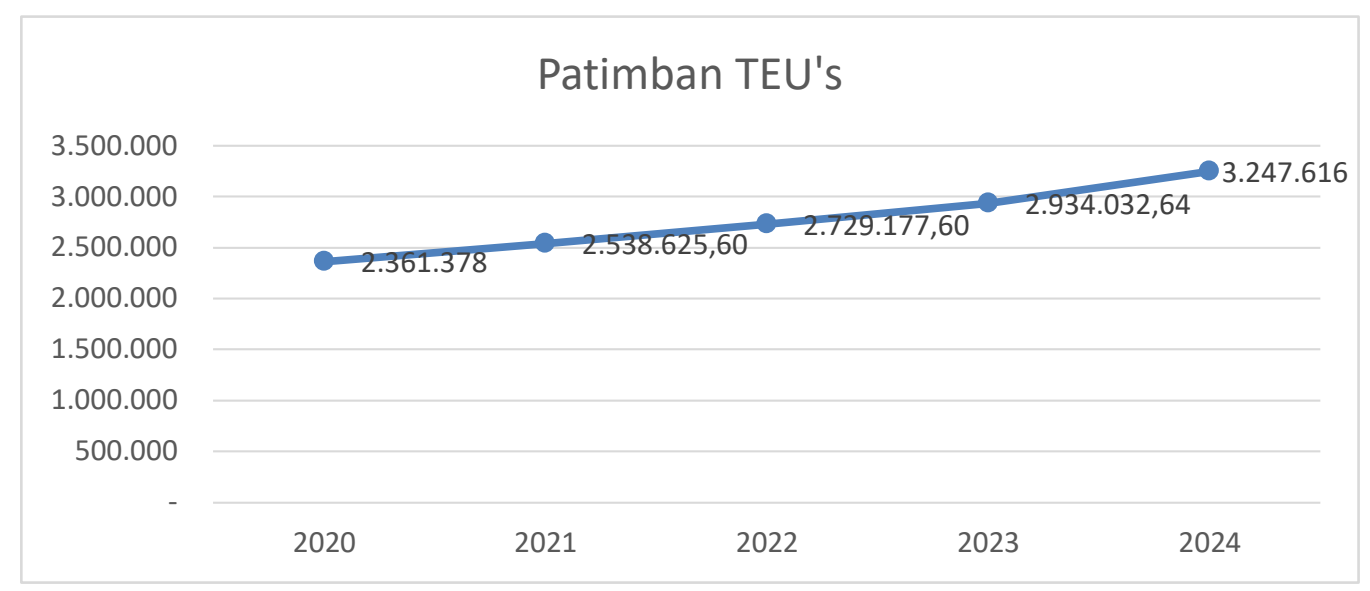

Gambar 6. Data Kajian JICA (2017) tentang potensi container yang ada di Pelabuhan Patimban sebesar 2.3 juta TEU - 3.2 juta TEU atau sekitar $30 \%$ dari Tanjung Priuk.

Berdasarkan data tersebut diatas, maka sebenarnya Pantai Kelapa patimban memiliki peluang yang cukup besar dalam pengembangan pariwisata berkelanjutan di masa mendatang. Akan tetapi situasi dan kondisi terkini mengantarkan perlunya dilakukan tahapan-tahapan yang sistematis untuk meletakan titik kebangkinan Pantai Kelapa Patimban sebagai destinasi wisata. Perlunya diadakan sebuah gelaran event, akan menandai upaya bangkitnya geliat pariwisata di wilayah tersebut. Akan tetapi tahapan-tahapan yang harus ditempuh tentu tidak sesederhana yang dibayangkan.

Studi rekreasi "leisure studies" sangat penting, utamanya dalam hal pemahaman penyelenggara "event", adanya konsep main "play", pengalaman berekreasi "leisure experience", kebutuhan, motivasi, keuntungan yang didapat pengunjung/peserta yang diterapkan dalam "event"nya. Manajemen taman dan objek wisata rekreasi bukan hanya bertanggungjawab terhadap pengadaan dan perawatan fasilitas yang disediakan di masing-masing "venue", tetapi juga bertanggungjawab terhadap pelayanan dan penyelenggaraan program-program 
kreatif yang mampu memberi pengalaman menyenangkan kepada pengunjung. Proses penyelenggaraan dimulai dari tahap perencanaan "planning", pengelolaan "management", sampai pada tahap pemasaran "marketing".

Selanjutnya Gerz (2007) mendefiniskan bahwa "event" merupakan alat komunikasi, media, dan pertunjukan, yang dijelaskan berikut ini :

- "Event" merupakan alat komunikasi yang digunakan oleh tim marketing suatu perusahaan/Lembaga/instansi untuk menyampaikan suatu informasi /pesan kepada masyarakat; dan juga untuk menginterpretasikan budaya.

- "Event" bukan hanya alat komunikasi, tetapi juga sebuah media untuk sebuah perubahan. Misalnya dalam sebuah "event" mengusung anti-golput, perubahan yang diharapkan yakni masyarakat akan memiliki kesadaran untuk berpartisipasi aktif dalam pemilu dan tidak golput.

- "Event" merupakan sebuah pertunjukan. Masing-masing "event" memiliki kekhasan sendiri-sendiri pada orangnya, dalam hal ini penyelenggara, pengisi acara, dan audience-nya; dresscode (baju), dan tempat penyelenggaraannya. Misalnya "event" olahraga sepakbola, maka di dalamnya ada yang berperan sebagai pemain speak bola dengan seragamnya, wasit, pelatih, dan penontonnya dengan juga menyesuaikan.

Studi budaya memberi pemahaman bahwa dalam sebuah "event", budaya merupakan salah satu hal yang penting dan harus selalu diperhatikan sebagaimana faktor sosial. Studi budaya ini memberikan pandangan yang kritis terhadap budaya pop yang saat ini menjelma di berbagai bentuk "event".

Kajian ini selanjutnya mengulas tentang makna "event" dan pengalaman yang dibentuknya. Dalam hal ini yaitu membahasa bagaimana acara diselenggarakan secara terorganisir, dan bagaimana makna yang dilekatkan kepada acara tersebut serta pengalaman yang ditawarkannya. Pengalaman oleh Gerz (2007) didefinisikan 
sebagai apa-apa yang diterima, dirasakan, atau dipelajari oleh seseorang dari dunia dan ia mengingatnya. Pengalaman pada suatu "event" didesain diantara seni dan sains, dan harus secara cermat mempertimbangkan psikologi untuk memahami secara lengkap interaksi antara manusia, keadaan, dan program maupun sistem manajemen. Dari segi setting, misalnya lokasi penyelenggaraan "event".

Menurut Getz (2007), sebuah "event" adalah suatu kejadian yang tidak bisa diulangi karena hanya terjadi satu kali. Acara terencana atau "planned event" meskipun memiliki wujud dan konsep yang sama tetapi selalu ada variabel lain dalam acara tersebut akan berbeda sehingga akan menimbulkan pengalaman yang berbeda. Perencanaan "event" adalah fenomena spasial-temporal, dan bersifat unik karena interaksi di antara pengaturan, orang, dan sistem manajemen - termasuk elemen desain dan program,

Pengalaman akan "event" secara umum "generic" dimaknai sebagai hal-hal yang diterima, dialami, dirasakan oleh seseorang ketika menghadiri sebuah "event". Sederhananya mengenai bagaimana seseorang merasa senang atau terhibur "having fun" ketika ia menghadiri sebuah "event". Pengalaman akan "event" secara khusus "specific" dimaknai sebagai pengalaman pengunjung yang sudah ia harapkan dengan menghadiri sebuah "event". Sederhananya pengunjung sudah berharap akan pengalaman seperti apa dan bagaimana yang akan ia dapatkan pada saat mengadiri sebuah "event". Misalnya ketika seseorang sudah memutuskan untuk menghadiri perayaan Nyepi di Bali, maka satu diantara pengalaman yang ia ingin dapatkan adalah bagaimana suasana sepi di Bali pada saat itu.

"Event" memberikan makna yang berbeda-beda, bergantung siapa yang memandangnya dan dengan kepentingan apa. Misalnya bagi masyarakat umum "event" dimaknai bersifat komersil yang merupakan bagian dari industry hiburan "entertainment industry". Namun dari segi kebudayaan lokal, sebuah "event" sebagaimana koin yang bermuka ganda, bisa jadi membawa ancaman jika 
bermuatan budaya global yang keras dan berpotensi menggerus karifan local. Akan tetapi juga bisa menjadi bentuk upaya pelestarian, jika "event" tersebut justru menyuguhkan kearifan budaya lokal.

Gerz (2007) membagi dua jenis makna yang dapat dibentuk dalam sebuah "event" yaitu:

1. Makna Personal (Personal Meaning), makna atas pengamatan seseorang terhadap "dunia” yang didapat setelah mengkonstruksi pengalaman yang diperoleh dari pengamatan tersebut di dalam kognisinya. Makna ini memberikan keutungan kepada seseorang, misalnya menjadi bagian dari sebuah komunitas atau masyarakat, merupakan hasil dari pengalaman berbagi dengan sesama. Ini selanjutnya berkaitan dengan bagaimana makna personal tersebut kemudian diterapkan dan memiliki kontibusi dalam penyelengaraan sebuah "Event".

2. Makna Sosial (Social Meaning), makna yang diwujudkan dalam sebuah "event" dengan mengutamakan nilai sosial, budaya, dan ekonomi. Mengutamakan budaya merupakan bagain penting dalam sebuah "event" akan tetapi sulit untuk diterapkan, namun mungkin.

\section{Kesimpulan dan Saran}

Penyelenggaraan "event" harus mempertimbangkan banyak hal dan tidak sesederhana menentukan "event"-nya dalam bidang apa, siapa pengisi acaranya, dan siapa target peserta/pengunjungnya. Terdapat banyak faktor yang harus diperhatikan untuk mendukung kelancaran penyelenggaraan "event" mulai dari tahap pra persiapan (event designing), persiapan (event preparation), penyelenggaraan (event execution), dan evaluasi (event evaluation). Terkait dengan keberlanjutan pariwisata di Pantai Kelapa Patimban Subang, maka gelaran event dapat menjadi sebuah alternative solusi yang dapat diupayakan untuk dilakukan. Banyak faktor 
Peluang Event Pariwisata dalam Mengatasi Unsustainability Tourism di Pantai Kelapa Patimban...

yang harus dipertimbangkan untuk menentukan pengembangan pariwisata berkelanjutan, Event pariwisata dapat menjadi pilihan yang tepat untuk membangkitkan kembali destinasi wisata yang hampir mati.

\section{Ucapan Terima Kasih}

Ucapan terima kasih kepada Bapak Dedi Dediyana (Komnas Perlindungan Anak Subang) yang telah membantu memberikan informasi yang penulis butuhkan terkait dengan nara sumber yang dibutuhkan untuk kajian ini.

\section{Daftar Pustaka}

Getz, Donald, 2007. "Event Studies : Theories, Research and Policy for Planned Event. Elsevier, Burlington USA.

Iswari. 2014. Keterkaitan Motivasi untuk Terlibat dan Konsep Diri Anggota Harley Davidson Club Indonesia Yogyakarta.

Pendit, Nyoman 2006. Ilmu Pariwisata : Sebuah Pengantar Perdana. Jakarta: Pradnya Paramita

Prasanti dan Indriani. 2017. Pemaknaan Simbol dalam Komunitas 'Brotherhood' (Konstruksi Makna Simbol sebagai Identitas Diri dalam Komunitas 'Brotherhood' di Bandung).

Listi. 2015. Gejala groupthink dalam komunikasi kelompok club motor Brotherhood Medan dalam rangka pengambilan keputusan.

Soemanagara, Darmawan. 2006. Marketing Communication: Taktik dan Strategi. Jakarta: PT Bhuana Ilmu Populer.

Walker, G. J.et all 2011. Leisure Satisfaction and Acculturative Stress : Te case of Chinesse - Canadian Immigrants. Journal of Leisure Research, Vol. 11 (5), pp. 307-245. 


\section{Profil Penulis}

R Hendro S. Arlianto, ST adalah mahasiswa Magister Pariwisata Berkelanjutan Sekolah Pasca Sarjana Universitas Padjadjaran yang menaruh perhatian dalam kajian Pengembangan Potensi pariwisata berkelanjutan di Pantai Kelapa Patimban Kabupaten Subang Jawa Barat. Menyelesaikan Studi S1 di Institut Teknologi Nasional (ITENAS) Bandung jurusan Teknik dan Manajemen Industri (TI). Email : rd.hendro.sa@gmail.com

Dr. Evi Novianti, S.Sos; M.Si, Ketua Program Studi Ilmu Pariwisata Berkelanjutan di Sekolah Pascasarjana Universitas Padjadjaran. Aktif dalam melakukan penelitian serta pengabdian kepada masyarakat di bidang Pariwisata Berkelanjutan.

Dr. Cipta Endyana, ST., MT, Geolog yang menaruh perhatian dalam mengembangkan kajian-kajian di bidang Pariwisara berkelanjutan. Saat ini menjabat sebagai Manajer Akademik dan Kemahasiswaan di Sekolah Pascasarjana Universitas Padjadjaran. 